\title{
Percepções femininas dos papéis sexuais do homem e da mulher de uma comunidade urbana da cidade de Passo Fundo*
}

Fernanda Garbin** Eleanor Moretti***

\section{RESUMO}

O presente estudo objetivou caracterizar as percepções dos papéis sexuais masculinos e femininos de mulheres residentes em uma comunidade urbana da cidade de Passo Fundo. Participaram da pesquisa nove mulheres, procurando-se evidenciar suas percepções em relação aos seus papéis sexuais, a origem desses, as influências em sua concepção, os papéis por elas pressupostos e a influência que as diferenças de papéis podem ter sobre a sua saúde. Os dados foram coletados com a utilização de um instrumentoguia, sendo, posteriormente, categorizados e analisados. Constataram-se cinco categorias: predominância da mulher como reprodutora, as figuras de Adão e Eva como precursores dos papéis sexuais, manutenção dos papéis sexuais tradicionais. Constatou-se, ainda, a interferência na saúde da mulher

* Pesquisa realizada coma requisito da disciplina de Iniciação a pesquisa Científica I e II e Métodos Quantitativos e Qualitativos.

** Acadêmica do curso de Enfermagem da Universidade de Passo Fundo.

*** Mestre em Enfermagem. Professora titular III das Disciplinas de Enfermagem na Saúde da Mulher I e II do Curso de Enfermagem da Universidade de Passo Fundo. 
pela propagação de doenças sexualmente transmissíveis. Em vista desses resultados, recomenda-se a continuidade do estudo para que se amplie a assistência da mulher e se desenvolvam programas de orientação sexual.

Unitermos: Percepções femininas, papéis sexuais, gênero, educação sexual.

\section{INTRODUÇÃO}

O mundo comemora as mudanças econômicas, políticas e sociais ocorridas principalmente nos últimos vinte anos, as quais levaram um grande número de mulheres a trabalhar fora de casa. A mulher deixou de ser a "dona de casa", que tinha como seus únicos "deveres" cuidar da casa, dos filhos e do marido, sem nada reivindicar ou usufruir. Através do movimento feminista, passou a conquistar espaços, dividir o mercado de trabalho e, finalmente, iniciar o longo trajeto em busca de sua valorização.

Essa mudança de comportamento da mulher gerou, contudo, outros conflitos, como a dificuldade de conciliar casamento, casa e filhos com a jornada diária de trabalho, a luta incessante para ser reconhecida, os baixos salários oferecidos, as condutas antiéticas enfrentadas, a falta de realização e, sobretudo, a dificuldade de identificar-se com esse novo papel.

Como profissionais da área da saúde e mulheres, observamos que há muito o que fazer. Evidenciamos a existência de uma grande desvalorização da mulher não apenas pelos homens e o mercado de trabalho, mas pelas próprias mulheres, que mantêm enraizados dentro de si os papéis sexuais tradicionais a elas atribuídos pela sociedade machista de outrora.

Kusnetzoff (1988, p. 22) explica essa desvalorização:

Todas as teorias predominantes em todas as épocas a respeito da mulher foram formuladas por homens. Não é de estranhar, portanto, que ela tenha sido considerada sempre inferior, com pouca força física e carência de níveis abstratos de pensamento. Muitas mulheres acabam acreditando piamente em tudo isto, com graves danos para sua posição social e seu desenvolvimento pessoal.

Estas teorias, que na realidade tem mais de mito que de qualquer outra coisa, fizeram da mulher um ser relegado ao espaço da casa, da preocupação com os filhos, ausente da vida pública e política, discriminada para estudar e para crescer profissionalmente.

Na busca de uma valorização de sua identidade como ser feminino, e não simplesmente como mulher, ela procura criar uma nova tendência, que se choca com as posturas sexuais tradicionais, originando conflitos morais e sociais, com o que a mulher não consegue determinar seu papel sexual. 
Os papéis sexuais são constituídos com base nas expectativas da sociedade, como descreve Cavalcantti (s.d., p. 237):

Cada sociedade tem os seus parâmetros do que considera próprio a cada gênero, e os indivíduos são moldados de conformidade com estes modelos, constituindo assim sua identidade sexual e desempenhando os papéis sexuais que são tidos como apropriados. A sociedade tem uma opção quase ilimitada para determinar e redeterminar papéis sexuais e variam de um grupo para outro, os antropólogos fazem estudos interculturais muito significativos.

Na mesma linha de pensamento, Kusnetzoff (1988, p. 20) define papéis sexuais como "uma expectativa, é o que a sociedade espera que as pessoas de determinado gênero cumpram". Não podemos, então, determinar o papel sexual sem levarmos em consideração o gênero de cada indivíduo. Para o mesmo autor, gênero é aquilo que uma pessoa diz ou faz para indicar se é homem ou mulher" (p. 19).

Já Tiba (1992) determina papel de gênero masculino e feminino, ou simplesmente sexual, aquele de homens e mulheres com características sociobiológicas, sendo que o papel masculino existe em função do feminino e vice-versa.

Para melhor compreender os mecanismos da formação dos papéis sexuais, é necessário observar as características biológicas e sociopsicoafetivas. Tiba (1992, p. 24) descreve como características biológicas a "bagagem hereditária humana, predeterminada geneticamente com características sexuais primárias e secundárias regidas pelas leis fisiogenéticas da maturação e que independem da vontade dos indivíduos".

As características sociopsicoafetivas são formadas com os elementos do meio familiar, escolar e religioso que a criança vai adquirindo desde que nasce, voluntária e involuntariamente, para formar a sua cultura sexual.

As distorções na concepção dos papéis sexuais atribuídos às mulheres são fruto da porção psicoafetiva. Uma dessas distorções é a concepção da mulher como simples reprodutora, maternal e responsável pela criação dos filhos e cuidados com o lar, sem nenhuma aspiração intelectual. Essa desvalorização de seu potencial intelectual coloca-a em posição de inferioridade em relação aos homens, determinando uma divisão discriminatória do trabalho e trazendo implicações para a sua qualidade de vida.

Com a finalidade de contribuir para a assistência integral a saúde da mulher, pretendemos conhecer as percepções das mulheres residentes em uma comunidade urbana da cidade de Passo Fundo sobre os papéis sexuais referentes ao homem e a mulher. Buscamos, através da identificação dos fatos que influenciam tais percepções, das tentativas de delimitá-los e da possível detecção de prejuízo à saúde da mulher, a contribuição para a 
construção de uma identidade digna para as mulheres. Nesse novo papel, a mulher não será vista através de suas características biológicas, mas, sim, pelos seus traços culturais, intelectuais e espirituais.

\section{METODOLOGIA}

Este é um estudo descritivo-interpretativo, de abordagem qualitativa, em que se valoriza a subjetividade e as características culturais de cada participante.

\section{Local e População}

Fizeram parte deste estudo descritivo nove mulheres que freqüentam o Serviço de Saúde da Mulher do Ambulatório Pedro Ávila, localizado no bairro Vera Cruz, ponto de referência da disciplina de Saúde da Mulher I e II, do curso de Enfermagem da Universidade de Passo Fundo.

A escolha foi realizada de maneira aleatória, levando-se em conta a disponibilidade e o desejo das mulheres de participarem desta pesquisa.

\section{Coleta e Análise dos Dados}

$\mathrm{Na}$ data combinada, das dez mulheres que se dispuseram a participar desta entrevista, compareceram nove, com idades entre 22 e 64 anos, grau de escolaridade variando de analfabeto a segundo grau completo, de descendência única variada, sendo a maioria brasileira, italiana e alemã. A profissão predominante foi a "do lar".

Todas foram reunidas em uma sala, onde lhes foram explicados os objetivos da pesquisa, assegurando-se o anonimato das participantes (identificadas com o nome de deusas gregas), direitos e deveres e o consentimento para que a entrevista fosse gravada, este último sendo negado por unanimidade.

Para identificação das falas, cada mulher recebeu um número de um a nove, atribuído pela entrevistadora. Iniciamos com um diálogo sobre sexualidade, saúde da mulher, importância do exame citopatológico para favorecer a desinibição do grupo, quando a tensão inicial foi quebrada, procedemos à entrevista utilizando as questões-guia previamente elaboradas (Anexo I).

Cada mulher emitia sua opinião sobre o tema em debate, a qual era anotada pela entrevistadora tal como se apresentava para o grupo de forma individual, identificado pelo número atribuído à participante. Assim todas 
as respostas foram emitidas em grupo e os diálogos foram transcritos individualmente, enriquecidos com comentários gerais do grupo. Após as questões terem sido todas respondidas e as respostas anotadas individualmente, essas foram lidas para cada participante, fazendo-se, assim, a validação das mesmas.

Encerrada a entrevista, o material obtido foi lido e relido exaustivamente, iniciando-se a análise de conteúdo com a unitarização, quando foram retiradas do texto as unidades de significado, que, por serem de certa maneira unânimes, coincidiram com as categorias encontradas. A descrição e interpretação foram num momento em que, através de texto-síntese, combinaram-se os resultados de todas as unidades incluídas em cada categoria de análise, procurando-se atingir a compreensão mais profunda do conteúdo das mensagens de cada categoria de análise.

A unitarização deixou evidente as seguintes unidades de significado: o papel sexual da mulher como reprodutora, a origem deste papel em Adão e Eva, a manutenção dos papéis tradicionais, a influência dos meios de comunicação, religião e sociedade na construção dos papéis sexuais e as doenças sexualmente transmissíveis como principal prejuízo para a saúde da mulher.

Pela semelhança entre as nove respostas obtidas, a unitarização e a categorização mostraram-se semelhantes, sendo uma a essência da outra. As categorias foram interpretadas de maneira a enfatizar a importância da fala de cada sujeito participante desta pesquisa.

Os nomes de deusas utilizados para manter o anonimato das mulheres que participaram desta entrevista foram: Afrodite (64 anos, do lar, descendência brasileira, analfabeta, cinco filhos, casada), Penélope (42 anos, diarista, descendência italiana, $1^{2}$ grau completo, três filhos, casada), Desdêmona (38 anos, do lar, descendência brasileira, $2^{2}$ grau incompleto, dois filhos, solteira), Égide (29 anos, secretária, descendência alemã, $2^{\mathrm{Q}}$ grau completo, solteira), Hera (22 anos, estudante, descendência brasileira, $2^{a}$ grau incompleto, solteira), Pandora ( 31 anos, do lar, descendência italiana, primeiro grau incompleto, quatro filhos, viúva), Metis (43 anos, diarista, descendência alemã, primeiro grau completo, três filhos, casada). Réia (26 anos, estudante, descendência italiana, segundo grau completo, dois filhos, solteira) e Cípria ( 56 anos, do lar, descendência italiana, $2^{\circ}$ grau incompleto, quatro filhos, viúva).

\section{DISCUSSÃO E INTERPRETAÇÃO}

Nos últimos anos, tem havido considerável interesse científico pelos estudos das diferenças e semelhanças entre os sexos. A influência histórica, as crenças a respeito das diferenças sexuais, a busca de uma auto-afirmação dos papéis sexuais de ambos os sexos, o choque entre as tendências modernas 
e o modelo tradicional tem se tornado o ponto-chave para a busca de uma melhor compreensão da repressão a feminilidade da mulher e do seu direito de cidadã, livre de desigualdades.

Muitas mudanças no coletivo já ocorreram para que essa meta fosse alcançada, mas o processo tem sido muito lento e as diferenças entre os papéis sexuais continuam predominando em nossa cultura. Procuramos, nesta pesquisa, demonstrar a existência dessas diferenças para, assim, incentivar a busca de soluções, contribuindo para a melhoria da saúde da mulher e, ainda participando da luta pelo direito de ser mulher e feminina.

Para o desenvolvimento da discussão, utilizamos categorias retiradas das falas das mulheres sujeitos desta pesquisa.

\section{A procriação como objetivo de vida. Papel sexual definido: macho e fêmea}

Para a maioria das mulheres desta pesquisa, o conceito de papel sexual restringe-se à reprodução, ao papel de ser mãe. Essa visão demonstra um grande distanciamento dos conceitos utilizados na busca da identidade feminina, nos quais o ideal é a valorização do ser feminina e mulher.

A representatividade quase unânime do macho e da fêmea em sua função reprodutora é uma característica do desenvolvimento histórico e social da formação dos gêneros. Com o decorrer da história, a humanidade, em sua busca da evolução, foi doutrinada a visualizar as mulheres como seres que promovem a reprodução e, com isso, a preservação da vida e da espécie. Para melhor ilustrar esse fato, retornamos aos tempos pré-helênicos e ao mito sobre a origem do planeta, relatado por Highwater (1992, p. 37-38)

No princípio era o Nada. O Nada existia sem tempo nem espaço, pois ele não conhecia o nascimento nem a destruição. Deste vácuo impensável surgiu Gaia (a deusa mãe), o grande mistério do ser, a fonte de todas as coisas. Foi assim que o mundo começou. Gaia tirou de seu corpo a terra e o mar. Ao mexer-se, a espinha dorsal arqueou, formando as altas montanhas. Na profundidade misteriosa de sua carne, fez os vales e as grutas, onde a sua voz ainda ecoa. Suspirou e assim se fez a chuva... as vergôneas brotavam de seus poros, e as flores abriam-se em seus múltiplos seios. Do corpo dela provinha toda a vida... de seu Ser misterioso nunca se interrompia a criação. Certo dia Gaia fez seis homens e seis mulheres e depositou-os suavemente sobre seu corpo... ai cresceram e se multiplicaram.

Utilizamos esse exemplo matricêntrico do surgimento da Terra porque nele se insere a essência do papel da mulher como ser reprodutor. Gaia, 
a deusa mãe/mulher, surgiu do nada para trazer a vida e originar homens e mulheres. Prosseguindo na narrativa do mito, conta o autor que Gaia é dominada e substituída por Apolo, o primeiro dos homens que surgiu de seu ventre. Gaia deixa de ser deusa e passa a ser a fonte da vida e da humanidade. Essa lenda data de aproximadamente 3.500 a.C.

Desse mesmo modo, existem diversos relatos de períodos históricos nos quais a mulher foi valorizada apenas pela sua capacidade reprodutora, que se constituía no único motivo para a sua existência. Retornando ao final do século XX, ano 2000, parece-nos, pela fala de Afrodite, que, mesmo 5.500 anos depois, nada ou pouco mudou: A mulher e o homem existem apenas para porem filhos no mundo e preservar a sua raça...

Como, então, discutir e comemorar as vitórias das mulheres em sua busca pelos direitos de igualdade, se ainda não conseguimos provar nossa capacidade intelectual, nossa capacidade de construir, contribuir e auxiliar a evolução histórica? A mulher não deve negar a sua capacidade de ser mãe, mas, sim, fazer dessa uma bênção recebida por ser mulher. Deve ensinar a seus filhos e semelhantes os traços e características que fazem dela um ser racional, hábil, intelectual e de uma sensibilidade que a coloca em "pé de igualdade" com os homens.

Não esperamos, com nosso trabalho, conseguir mudanças imediatas após tantos séculos de repressão, mas contribuir para que a história tome um novo rumo, no qual a feminilidade seja valorizada. A sociedade necessita perceber o feminino nas mulheres para conceber seu conceito de gênero, no qual a reprodução seja apenas mais uma característica de ser mulher.

\section{A origem: Adão e Eva}

Quando questionadas sobre a origem desses papéis sexuais, a maioria das entrevistadas atribuiu-a ao principio dos tempos, sendo citados com maior freqüência Adão e Eva. Disse Penélope: Estes papéis existem desde que Cristo fez Adão e Eva e tudo ficou assim. Desdémona complementou essa visão unânime da origem do papel sexual: Desde Adão e Eva que o mundo é mundo e tudo é assim.

A referenda a Adão e Eva como precursores dos papéis sexuais nos transporta para a antiquíssima visão judaico-cristã (patriarcal), na qual a mulher recebeu a influência do mito da "má Eva", criatura indisciplinada e fortemente assexuada: "Eva foi feita de uma costela de Adão, isto é, do homem para o homem, e, por esta razão, é considerada inferior e mais fraca. Ao mesmo tempo é considerada o instrumento por meio do qual o pecado veio ao mundo, a tentadora que persuadiu Adão a comer o fruto proibido." (Highwater, 1992, p. 30).

A mulher, apesar de ser identificada em seu papel de mãe, mantém uma forte ligação com o papel de pecadora, por isso é vista como ser inferior. 
Mais um vez, as mulheres deparam-se com a dificuldade de se identificarem em seu papel sexual e dividem-se entre a inocência de Maria e a lúbrica intencionalidade de Eva. Em correlação a esse fato, Égide comenta: ... $a$ mulher provou o fruto proibido, realizou o pecado e foi condenada por Deus a trabalhar em casa, ter os seus filhos, criar seus filhos e servir o marido com muito respeito.

A manutenção de mitos e preceitos demonstra que a história e a sociedade, juntamente com o caráter psicoafetivo, são as principais variáveis que determinam a formação dos papéis sexuais. Esse tratamento ambíguo que as classifica em "boas e más", "santas e pecadoras" ocasionou um pacto silencioso entre homens e mulheres e ainda que impera vergonhosamente. Se assexuadas, as mulheres são vistas como virtuosas, afetivas, boas mães, sendo-lhes reservada a proteção masculina e um "bom marido", ao contrário, se demonstram seu desejo, são consideradas sem moral, dignas apenas da humilhação.

Apesar da liberdade sexual de hoje, a mulher vive aprisionada as concepções de séculos passados, preservando a imagem de mulher "frígida", que não se interessa por sexo e é incapaz de sentir prazer. Abre mão, assim, de sua satisfação, de seu desejo e de sua realização como mulher para evitar que a imagem maternal seja distorcida ou renegada.

A origem dos papéis sexuais ocorre, fundamentalmente, na infância, através do processo de socialização, a partir do que a sociedade determina os papéis masculino e feminino. Nesse processo as crianças constróem a sua identidade sexual e de gênero. Hera nos diz que: ... cada um transforma, muda de acordo com a educação que recebe, ser homem ou mulher depende da criação dada pelos nossos pais.

Em função disso, é preciso redeterminar as crenças sociais para recriar os papéis sexuais, proporcionando as mulheres o direito de agirem sem serem recriminadas.

\section{Prevalência dos papéis sexuais tradicionais: o homem como provedor e a mulher como reprodutora e criadora}

Mais uma vez, o passado integra-se à percepção atual dos papéis sexuais. $\mathrm{O}$ homem e a mulher são visualizados através de uma concepção conservadora e tradicional. Pandora, durante sua fala, deixa-nos isso evidente: Quem escolhe o casamento deve viver bem nele. $O$ homem deve trabalhar para sustentar da casa e não deixar que nada falte à família. A mulher "bota" os filhos no mundo, cuida da casa, dos filhos e do marido [suspiros]. É que a gente não tem estudo e assim não pode trabalhar fora de casa.

Nessa percepção, o homem é o provedor do sustento, isto é, trabalha fora, traz o sustento da família, realiza-se fora de casa, no espaço público; já 
à mulher cabem a maternidade como principal atribuição, o cuidado da casa e dos filhos, a tarefa de guardiã do afeto e da moral na família.

Faria (1997, p. 11) revela que "a persistência deste modelo costuma ser justificada pela idéia de que estes papéis são naturais, isto é, homens e mulheres nascem para serem deste jeito. É o mecanismo da naturalização." Essa ideologia tenta fazer crer que a realidade é fruto da biologia e de uma essência masculina e feminina.

Essa concepção, entretanto, aos poucos, está sendo questionada pelas mulheres, que, cada vez mais, procuram reivindicar seus direitos e não mais se contentar com seu papel de donas de casa, afrontando a postura masculina, descrita por Kusnetzoff (1988, p. 20):

Os homens se acostumaram a ver as mulheres em lugares $e$ atitudes domésticas: cuidando dos filhos, lavando roupas, cozinhando. Vê-las ocupando cargos públicos costuma ser muito chocante. Se uma mulher atua nos negócios, na política, ou em alguma profissão, pode ser chamada de "agressiva", ou "тиlher-macho", qualificativos que evidenciam a mágoa pela mudança de imagem. Esperávamos outra coisa, os papéis tradicionais se alteraram e nos resistimos à mudança.

Apesar desses ressentimentos, hoje já encontramos em nosso meio homens usando trajes tradicionais, ao mesmo tempo em que há os que usam brincos e cabelos compridos. É comum, também, vermos e ouvirmos falar de pessoas que se submeteram a cirurgias para mudar de sexo. Vemos, ainda, como resultado dessas tendências, a modificação na forma de criar e educar os filhos. Os pais mais jovens estão educando seus filhos de forma menos rígida quanto a determinação de papéis sexuais masculinos e femininos.

\section{A formação dos papéis sexuais recebe a influência dos meios de comunicação de massa, da religião, da sexualidade e da educação formal e informal}

Realmente, devemos concordar em que as variáveis da formação dos papéis sexuais estão sujeitas as influências relacionadas, as quais, porém, também podem ser grandes aliadas na busca de uma nova concepção dos papéis sexuais.

Metis, outra das nossas entrevistadas, expõem de maneira simples essa ambigüidade, utilizando como exemplo a televisão: ... da mesma forma que a TV nos dá a informação para aprender coisas novas ela também nos ensina coisas erradas, mas que são mostradas de maneira bonita, não parecendo assim tão erradas. 
Os meios de comunicação, por vezes, têm se posicionado de maneira contraditória a nossa busca de igualdade e liberdade. Apesar de dedicarem espaços para a causa feminista, sua heterogeneidade também trata as mulheres de forma a reforçar seu papel tradicional.

A mulher aparece de maneira estereotipada especialmente durante o horário "nobre"; é humilhada em programas humorísticos; a imprensa escrita ignora a sede de conhecimento das mulheres e dedica-lhes apenas páginas de culinária, moda, decoração, beleza, conselhos sobre como cuidar dos filhos e como "agarrar", agradar e conservar um marido. As revistas masculinas, por sua vez, exploram o corpo feminino, tratando-o como objeto sexual para o desfrute alheio.

Assim, a dualidade das concepções dos papéis sexuais, que divide as mulheres em pecadoras e maternais, mais uma vez prevalece. Ao mesmo tempo em que a mídia propaga a imagem da mulher "perfeita" boa mãe, excelente esposa, caprichosa nos afazeres domésticos, difunde $\mathrm{cm}$ massa $\mathrm{o}$ corpo da mulher como objeto de prazer.

A religião, por sua vez, durante séculos, determinou os papéis sexuais do homem e da mulher através de sua influência, que ainda domina na sociedade ocidental. No Gênesis, reforça-se a postura andrôcentrica logo após a mulher ter provado o fruto proibido. Disse o Senhor Deus para ela: "Multiplicarei os sofrimentos de sua gravidez. Entre dotes dará a luz os filhos, a paixão arrastar-te-á para o marido e ele te dominará" (Highwater, 1992, p. 103).

Desde a criação, a religião determina que a mulher é um ser inferior, cujo destino é dar a luz a seus filhos, criá-los e servir ao marido que a dominará. Após séculos de introjeção desses conceitos, toma-se difícil e ela se libertar das amarras, mesmo reconhecendo suas potencialidades. O medo de contrariar a tradição não permite que a mulher conquiste seu lugar de direito.

Não consideramos a sociedade e a educação influências primárias na formação dos papéis sexuais. Acreditamos que a sociedade é fruto da interferência histórica da desvalorização da mulher. São esses valores passados de geração para geração que deformam as percepções dos papéis sexuais e impedem a conquista do direito de sermos femininas além de mulheres.

\section{As diferenças dos papéis sexuais interferem na saúde da mulher, principalmente pela propagação das doenças sexualmente transmissíveis}

A saúde da mulher tem sido objeto de numerosas análises e considerações no âmbito das ciências da saúde, de tal forma começam a aparecer novas contribuições conceptuais relacionadas com a saúde da mulher. $\mathrm{Na}$ literatura médica e de saúde pública, nota-se uma ênfase nos aspectos clínicos 
e epidemiológicos dos riscos e danos que a afetam, especialmente os associados a gravidez, parto e pós-parto. Esses estudos e os que se relacionam com a descrição das diferenças sociais entre os sexos produziram conhecimentos valiosos que permitiram avançar no próprio desenvolvimento teórico e metodológico dos estudos sobre a mulher.

Entretanto, apesar de todo esse desenvolvimento, Réia expõe uma das inúmeras dificuldades geradas pelas diferenças dos papéis sexuais. Diz ela: ... a mulher pouco se previne das doenças sexuais por falta de conhecimentos e porque o marido ou o namorado pode achar que ela não confia nele. Cipria complementa este relato ao relacionar as doenças sexualmente transmissíveis causadas pela infidelidade masculina: ... os homens traem as mulheres e trazem as doenças que nos mata para casa.

É quase desumano acreditar que, apesar da existência do preservativo e de toda a divulgação realizada para a prevenção das DSTs, esse método não seja ainda utilizado por preconceito. A mulher continua a ser tratada como objeto sexual, sendo valorizados apenas os seus aspectos biológicos. Apesar disso, como parceira sexual, não pode manifestar sen desejo ou demonstrar sen prazer.

Essas percepções são observadas ainda ao término do século $\mathrm{XX}$, o que nos leva a questionar as conquistas difundidas em relação a igualdade dos papéis sexuais. É necessário que se analise a mulher além do plano biológico e da demografia, enfocando-a como uma categoria de análise socialmente construída, adentrando, assim, no terreno das seções de gênero, no que significa "ser homem" e "ser mulher" e nas manifestações de saúde e doença como processo social, com raízes históricas.

Através dessas mudanças, possibilita-se um novo conceito do papel sexual da mulher, valorizando-a e tratando-a com o respeito que há muito lhe é devido.

\section{CONSIDERAÇÕES FINAIS}

Temos este estudo como um processo, parte de uma vivência e que, portanto, não se esgota aqui. Optamos pelo termo por observarmos as discriminações, os preconceitos e a falta de credibilidade no tratamento dispensado a maioria das mulheres.

Essa desigualdade de papéis parece-nos tão evidente que se torna difícil comemorar as conquistas do movimento feminista. A falta de uma concepção moderna dos papéis sexuais, somada a bagagem histórica de repressão, nos fez questionar se, realmente, as mulheres estão conquistando o sen lugar.

A vivência proporcionada pelo desenvolvimento deste trabalho foi muito valiosa para nós, tanto como mulheres quanto como profissionais. Como mulheres, por termos a oportunidade de contribuir, mesmo que de 
forma incipiente, para a reformulação dos papéis sexuais; como profissionais, por nos oportunizar um conhecimento mais aprofundado da natureza da mulher e, com isso, tornarmo-nos mais sensíveis a suas histórias e aos mitos que carregam dentro de si. Acreditamos que essa experiência nos auxiliará durante a assistência de enfermagem, pois poderemos ver a mulher como um todo, integrada ao meio onde vive.

Vale ressaltar também os aspectos éticos envolvidos neste estudo, que, pela natureza e complexidade do tema, tornam sua abordagem delicada, sendo necessário várias leituras e reflexões para contornar tais dificuldades.

Nosso desafio é contribuir para que, num nível individual, mais e mais mulheres alcancem maior autonomia. No entanto, sabemos que, para algumas mulheres, pode parecer um pouco estranho pensar que podem escolher, manifestar os seus desejos sem serem castigadas, que podem dizer "não" com convicção e acreditar que suas idéias são legitimas. É preciso crescer, conquistar este lugar que é nosso por direito, cortar as amarras que nos prendem, que dominam e impedem a nossa realização.

Para um maior crescimento social, é necessário que se reconheça o valor da mulher. Nós mulheres devemos refletir sobre a nossa existência e nossas possibilidades, pois, a medida que formos nos conscientizando desse nosso valor, missão, presença na sociedade iremos atingindo maior emancipação.

Precisamos criticar os aspectos que queremos mudar nessa construção tradicional, educar para a eliminação dessas diferenças e valorizar as ações coletivas das mulheres. É preciso reconhecer os mecanismos que são utilizados via desvalorização feminina e reconstruir uma visão do que é ser mulher e ser homem, reformulando a visão de suas relações e práticas sociais.

Mais um passo foi dado na busca da reconstrução desses papéis. Esperamos que muitos outros ainda sejam dados para que a mulher conquiste o seu lugar, pois, quando se sonha só, é apenas um sonho, mas quando sonhamos em conjunto é o início de uma nova realidade. Acreditamos, portanto, ter atingido com sucesso os objetivos propostos por este estudo e esperamos ter colaborado com a luta das mulheres na busca da tão sonhada igualdade feminina.

\section{REFERÊNCIAS BIBLIOGRÁFICAS}

1. CAVALCANTI, R. C. Saúde sexual e reprodutiva; ensinando a ensinar. Artgraf Editora, S.D.

2. FARIA, N.; NOBRE, M. Gênero e desigualdade. São Paulo: SOF, 1997.

3. HIGHWATER, J. Mito e sexualidade. São Paulo: Saraiva, 1992.

4. KUSNETZOFF, J. C. A mulher sexualmente feliz. 5. ed. Rio de Janeiro: Nova Fronteira, 1988.

5. TIBA, I. Sexo e adolescência. São Paulo: Ática, 1992. 


\section{ANEXO}

\section{I - INSTRUMENTO-GUIA}

\section{Dados de Identificação}

1- Nome fictício:

2- Idade:

3- Grau de instrução:

4- Profissão:

5- Procedência: 6- Etnia:

1. Quais os papéis sexuais referentes ao homem e a mulher que você percebe nas comunidades urbanas de Passo Fundo?

2. Quais são as origens desses papéis?

3. Que papéis sexuais se espera que o homem e a mulher desempenhem nos dias atuais?

4. Cite fatores que influenciam na determinação dos papéis sexuais do homem e da mulher nas comunidades urbanas de Passo Fundo.

5. Em que as diferenças de papéis sexuais do homem e da mulher das comunidades urbanas influenciam na saúde da mulher? 